\title{
Metastatic lymph node in gastric cancer; Is it a real distant metastasis?
}

\author{
Do Hyoung Lim, Hyeong Su Kim²†, Young Suk Park ${ }^{1 *}$, Jeeyun Lee ${ }^{1}$, Se Hoon Park1, Ho Yeong Lim', Sang Hoon Ji', \\ Min Jae Park', Seong Yoon $\mathrm{Yi}^{1}$, Ji Yeong An ${ }^{3,5}$, Tae Sung Sohn ${ }^{3}$, Jae Hyoung $\mathrm{Noh}^{3}$, Jae Moon Bae ${ }^{3}$, Sung Kim ${ }^{3}$, \\ Cheol Keun Park', Won Ki Kang ${ }^{1}$
}

\begin{abstract}
Background: Currently, the TNM staging system is a widely accepted method for assessing the prognosis of the disease and planning therapeutic strategies for cancer. Of the TNM system, the extent of lymph node involvement is the most important independent prognostic factor for gastric cancer. The aim of our study is to evaluate the survival and prognosis of gastric cancer patients with LN\#12 or \#13 involvement only and to assess the impact of anatomic regions of primary gastric tumor on survival in this particular subset of patients.
\end{abstract}

Methods: Among data of 1,008 stage IV gastric cancer patients who received curative R0 gastrectomy, a total of 79 patients with LN\#12 $(n=68)$ and/or \#13 $(n=11)$ were identified. All patients performed gastrectomy with D2 or D3 lymph node dissection.

Results: In 79 patients with LN\#12/13 involvement, the estimated one-, three- and five-year survival rate was $77.2 \%, 41.8 \%$ and $26.6 \%$ respectively. When we compared the patients with LN\#12/13 involvement to those without involvement, there was no significant difference in OS (21.0 months vs. 25.0 months, respectively; $\mathrm{P}=$ 0.140). However, OS was significantly longer in patients with LN\#12/13 involvement only than in those with M1 lymph node involvement (14.3 months; $P=0.001)$. There was a significant difference in survival according to anatomic locations of the primary tumor (lower to mid-body vs. high body or whole stomach): 26.5 vs. 9.2 months $(P=0.009)$. In Cox proportional hazard analysis, only $N$ stage $(p=0.002)$ had significance to predict poor survival.

Conclusion: In this study we found that curatively resected gastric cancer patients with pathologic involvement of LN \#12 and/or LN \#13 had favorable survival outcome, especially those with primary tumor location of mid-body to antrum. Prospective analysis of survival in gastric cancer patients with L N\#12 or \#13 metastasis is warranted especially with regards to primary tumor location.

\section{Background}

In Korea, gastric cancer is one of the most common causes of cancer-related death [1]. Currently, the tumor, node, metastasis (TNM) staging system is a widely accepted method for assessing the prognosis of the disease and planning therapeutic strategies [2]. Of the TNM system, the extent of lymph node involvement is the most important independent prognostic factor for gastric cancer [3]. These prerequisites were taken into account in the new TNM classification established in

\footnotetext{
* Correspondence: psy27hmo@skku.edu

† Contributed equally

${ }^{1}$ Division of Hematology and Oncology, Department of Medicine, Samsung Medical Center, Sungkyunkwan University School of Medicine, Seoul, Korea
}

2002 by the Union Internationale Contra le Cancer (UICC) and American Joint Committee on Cancer (AJCC). The 4th N-classification was based on the sites of lymph node metastasis (less than or greater than $3 \mathrm{~cm}$ from the primary tumor) [4,5], whereas in 5th (1997) and 6th (2002) TNM editions, the N staging was based on the number of metastatic lymph nodes [6-9].

In the 6th edition of AJCC TNM classification [7], however, metastasis to intra-abdominal lymph nodes, such as hepatoduodenal, retropancreatic, mesenteric, and para-aortic, are still categorized as distant metastases. In support of this, Roder et al also categorized hepatoduodenal ligament lymph node involvement as distant metastasis [10]. In Japanese Gastric Cancer
Ciomed Central 
Association (JGCA) N-classification, every single lymph node was numbered as station (\#1 to \#112) and grouped by anatomical position [11]. According to the Japanese classification, hepatoduodenal lymph node is further numbered as station 12 (\#12) and sub-classified as \#12a (left hepatoduodenal lymph node) and \#12b, p (posterior hepatoduodenal lymph node). Any lymph node stations greater than \#12b are considered group 3 or distant metastases, and subsequently being categorized as stage IV gastric cancer.

Despite of such classification, several studies have demonstrated favorable survival in subsets of patients with lymph node metastases only. Chung et al. reported favorable outcomes of 5 -year survival reaching $47.2 \%$ in a subgroup of gastric cancer patients with lymph node \#12 to \#14 metastases only [12], which is considerably higher than those reported for the historical control $[13,14]$. One of the plausible explanations for favorable survival in this particular group of patients may owe to different lymphatic drainage system depending on varying anatomic sites of the stomach. Upper third lymphatic vessels drain along left gastric, posterior gastric and splenic artery; whereas the lower third drains via common hepatic and superior mesenteric artery. Middle third stomach has a mixed drainage in both ways. All these vessels are eventually connected to the para-aortic lymphatic network [15-17]. Hence, the anatomic site of gastric cancer may be important when categorizing lymph node stations as distant metastases.

The aim of our study is to evaluate the survival and prognosis of gastric cancer patients with LN\#12 or \#13 involvement only and to assess the impact of anatomic regions of primary gastric tumor on survival in this subset of patients.

\section{Methods}

We reviewed surgical records and pathologic data of 5,687 patients with gastric adenocarcinoma who underwent gastrectomies between January 1995 and December 2002 at Samsung Medical Center. All of the included patients were restaged according to the $6^{\text {th }}$ edition of AJCC and UICC $[7,9]$. In addition metastatic lymph node stations were classified according to the $2^{\text {nd }}$ English edition of Japanese classification of gastric carcinoma [11]. Among these, curative R0 resection was performed in 1,008 stage IV patients including 79 patients with pathologically confirmed hepatoduodenal lymph node involvement (LN\#12, $\mathrm{n}=68$ ) and/or LN\#13 ( $\mathrm{n}=$ 11) only. The outcomes of the 1,008 stage IV patients who received curative gastric resection will be reported elsewhere: in brief, the median age was 57 years (range, 25-75 years), and the estimated median overall survival (OS) was 20.1 months. All patients received gastric resection and D2 or D3 lymphadenectomy. While our department policy usually recommends removal of $\mathrm{LN \# 12}$ and \#13, pathologic examination of LN\#12a from the other nodes of the hepatoduodenal ligament was seldom performed. Macroscopic findings of tumor and microscopic tumor growth patterns were described by Bormann type and Lauren classification, respectively.

Written informed consent was given by all patients prior to surgery according to institutional guidelines, and the study was approved by the Samsung Medical Center (Seoul, Korea) institutional review board and any ethical approval was not required. After gastrectomy, two-thirds of the patients were treated with postoperative adjuvant chemotherapy (57\%) or chemoradiotherapy (10\%). While our department policy usually recommends adjuvant treatment if the tumor stages Ib to IV, decisions regarding postoperative treatment were individualized by the treating physician. Chemotherapy regimens were mostly cisplatin-based doublets, and chemoradiotherapy consisted of 45 Gy of radiation with leucovorin and 5-fluorouracil.

The starting point of OS was the day of gastric resection. Time to death, whatever the cause, was used to calculate OS. Investigation of the relationship between the lymph node status and OS was conducted using univariate and multivariate analyses. Survival curves and their confidence intervals (CI) were calculated according to the KaplanMeier method. The log rank test was used to assess the statistical differences between groups, and the Chi-square test was applied to assess differences in the distribution of patients among groups. To identify the factors that might be of independent significance in influencing the OS, Cox proportional regression model was fitted.

\section{Results}

When the 1,008 stage IV gastric cancer patients were divided according to LN\#12/13 involvement only or others, there were no differences in the baseline characteristics including age, sex, histological grades and postoperative treatment. The demographic and histopathologic data of the 79 patients with lymph node \#12/13 involvement are provided in Table 1 . The most common site of primary tumor was antrum (63\%), followed by mid-body (23\%), upper body (11\%), and the whole stomach (3\%). Type of macroscopic finding was Bormann type III (66\%) in two-thirds, and approximately half of the patients had diffuse type in Lauren classification. The distributions of $\mathrm{T}$ stage were as follows: T1 (0\%), T2 (38\%), T3 (52\%), and T4 (10\%). With a median follow-up duration of 30 months, the estimated median OS was 21.0 months (95\% CI, 12.6-29.5 months). The patients had an estimated one-, three- and five-year survival rate of $77.2 \%, 41.8 \%$ and $26.6 \%$ respectively (Figure 1) and median disease-free survival was 28.5 months (Figure 2). When we compared the patients 
with LN\#12/13 involvement to those without involvement (i.e., T4 and/or N3 disease), there was no significant difference in OS (21.0 months vs. 25.0 months, respectively; $\mathrm{P}=0.140$ ). However, $\mathrm{OS}$ was significantly longer in patients with LN\#12/13 involvement only than in those with M1 lymph node involvement (14.3 months; $\mathrm{P}=0.001$ ).

There was a significant difference in survival according to anatomic locations of the primary tumor (lower to mid-body vs. high body or whole stomach): 26.5 (95\% C.I; 10.6 - 42.3) months vs. 9.2 (95\% C.I; 0.0 - 19.7) months, respectively $(P=0.009)$ (Figure 3). However, there were no significant differences in clinical variables between the two tumor location groups except for types of surgery of the extent of lymph node dissection due to anatomic locations (Table 2). No significant difference in the distribution of $\mathrm{N}$ stage was observed $(\mathrm{p}=0.066)$.

In the univariate analysis applied to $79 \mathrm{LN \# 12/13}$ patients, OS was significantly longer in patients with low to mid body tumors (26.5 months) than in those with high body or whole stomach tumors $(9.2$ months, $P=0.012)$. Other factors associated with longer OS were Bormann type (I-II vs. III-IV, $\mathrm{P}=0.031), \mathrm{N}$ stage $(\mathrm{p}<0.001)$, type of gastrectomy $(\mathrm{p}=0.014)$, and extent of surgery $(\mathrm{p}=0.006)$ (Table 3$)$. In Cox proportional hazard analysis, only $\mathrm{N}$ stage $(\mathrm{p}=0.002)$ retained its statistical significance to predict prognosis (Table 4). The anatomic location of primary gastric tumor did not significantly influence on survival of gastric cancer patients with $\mathrm{LN \# 12}$ and/or LN\#13 involvement at multivariate level $(\mathrm{P}=0.906)$.

\section{Discussion}

In this study, we found that curatively resected gastric cancer patients with pathologic involvement of LN \#12 and/or LN \#13 had favorable survival outcome, especially those with primary tumor location of mid-body to antrum. To the best of our knowledge, there are no previous reports focusing on LN \#12 and LN \#13 involvements in gastric cancer. According to the UICC/AJCC 6th edition [7,9], hepatoduodenal lymph node (LN \#12) and retropancreatic lymph node (LN\#13) are categorized as distant (M1) metastatic lymph node. Although limited by inherent bias from retrospective analyses, our study showed that LN \#12 and/or LN \#13 pathologic metastases pursue discrete natural history apart from metastatic M1 disease [13,14]. Furthermore, there are several lines of evidence to support that gastric cancer with metastatic lymph nodes only have more favorable clinical outcome when compared to those with distant metastasis. Five-year survival rate of pN3 gastric cancer
Table 1 Patient characteristics

\begin{tabular}{|c|c|}
\hline Clinical variables & Patient No (\%) \\
\hline \multicolumn{2}{|l|}{ Sex (Number) } \\
\hline Male & $53(67.1)$ \\
\hline Female & $26(32.9)$ \\
\hline \multicolumn{2}{|l|}{ Age (years) } \\
\hline Median & 57 \\
\hline Range & $25-75$ \\
\hline \multicolumn{2}{|c|}{ ECOG performance status (Number) } \\
\hline 0 & $10(12.7)$ \\
\hline 1 & $68(86.1)$ \\
\hline 2 & $1(1.3)$ \\
\hline \multicolumn{2}{|l|}{ Bormann type (Number) } \\
\hline । & 0 \\
\hline$\|$ & $17(21.5)$ \\
\hline III & $52(65.8)$ \\
\hline IV & $10(12.7)$ \\
\hline \multicolumn{2}{|c|}{ Lymph node dissection (Number) } \\
\hline D2 & $76(96.2)$ \\
\hline D3 & $3(3.8)$ \\
\hline \multicolumn{2}{|l|}{ Lauren classification (Number) } \\
\hline Intestinal & $20(25.3)$ \\
\hline Diffuse & $38(48.1)$ \\
\hline Mixed & $4(5.1)$ \\
\hline Unknown & $17(21.5)$ \\
\hline \multicolumn{2}{|l|}{ Histological grade } \\
\hline Well to moderate & $23(29.1)$ \\
\hline Poor to undifferentiated & $56(70.9)$ \\
\hline \multicolumn{2}{|l|}{$\bar{T}$ staging (Number) } \\
\hline $\mathrm{T} 1$ & 0 \\
\hline $\mathrm{T} 2$ & $30(38.0)$ \\
\hline T3 & $41(51.9)$ \\
\hline $\mathrm{T} 4$ & $8(10.1)$ \\
\hline \multicolumn{2}{|l|}{$\mathrm{N}$ staging (Number) } \\
\hline N1 & $14(17.7)$ \\
\hline N2 & $25(31.6)$ \\
\hline N3 & $40(50.6)$ \\
\hline \multicolumn{2}{|c|}{ Metastatic lymph node station (Number) } \\
\hline$\# 12$ & $69(87.3)$ \\
\hline$\# 13$ & $10(12.7)$ \\
\hline \multicolumn{2}{|c|}{ Post-operation treatment (Number) } \\
\hline None & $21(26.6)$ \\
\hline Chemotherapy & $48(60.8)$ \\
\hline Chemo-radiation & $8(10.1)$ \\
\hline Unknown & $2(2.5)$ \\
\hline \multicolumn{2}{|l|}{ Primary site (Number) } \\
\hline Upper body & $9(11.4)$ \\
\hline Mid-body & $18(22.8)$ \\
\hline Lower body & $50(63.3)$ \\
\hline Whole stomach & $2(2.5)$ \\
\hline
\end{tabular}




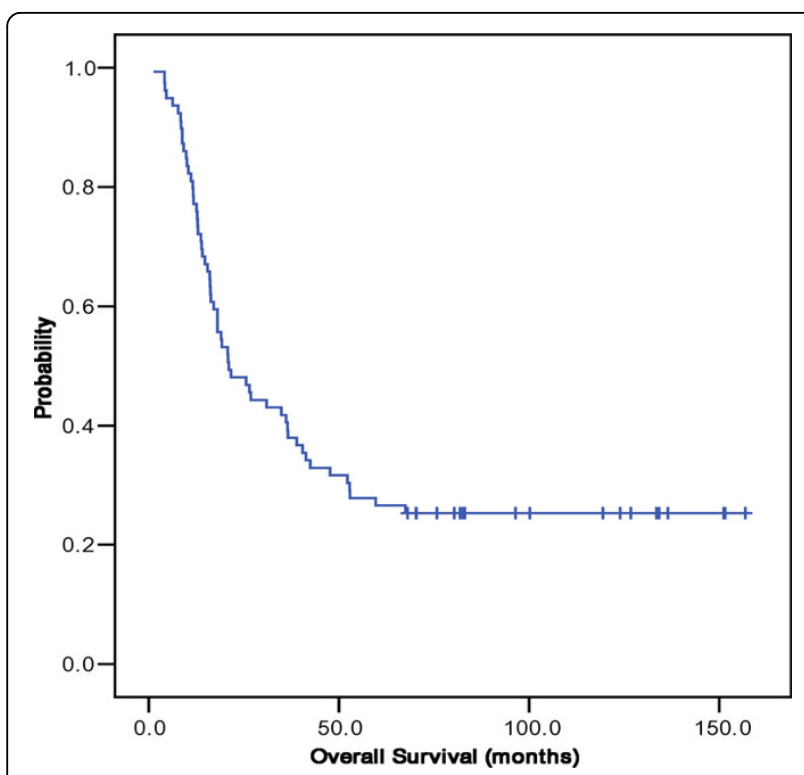

Figure 1 Overall survival. Kaplan-Meier overall survival curve. The median overall survival was 21.0 (95\% C.I; 12.6-29.5) months.

which was defined according to the 2002 AJCC staging system ranged between $10.5 \%$ and $13 \%$ in previous studies $[18,19]$. Based on our study, five-year overall survival rate of patients with $\mathrm{LN \# 12}$ and/or LN\#13 positive gastric cancer with primary tumor at antrum to body was $29.4 \%$. These survival rate is comparable to that reported for curatively resected stage IIIA or IIIB gastric cancer as a historical cohort group [20]. Furthermore, we previously reported outcomes of postoperative

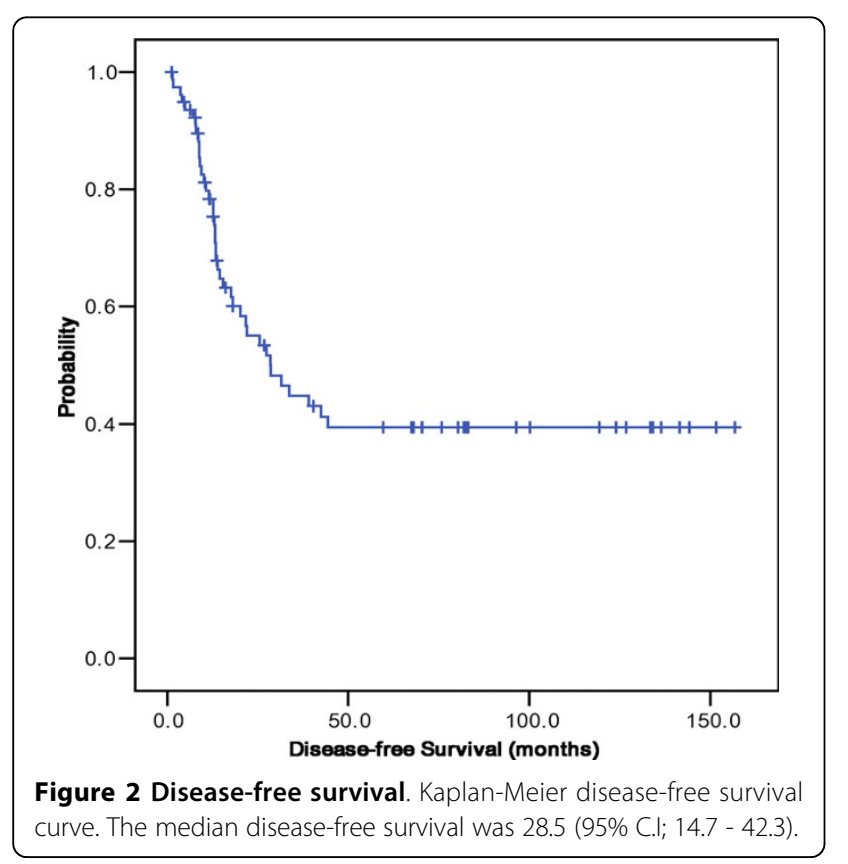

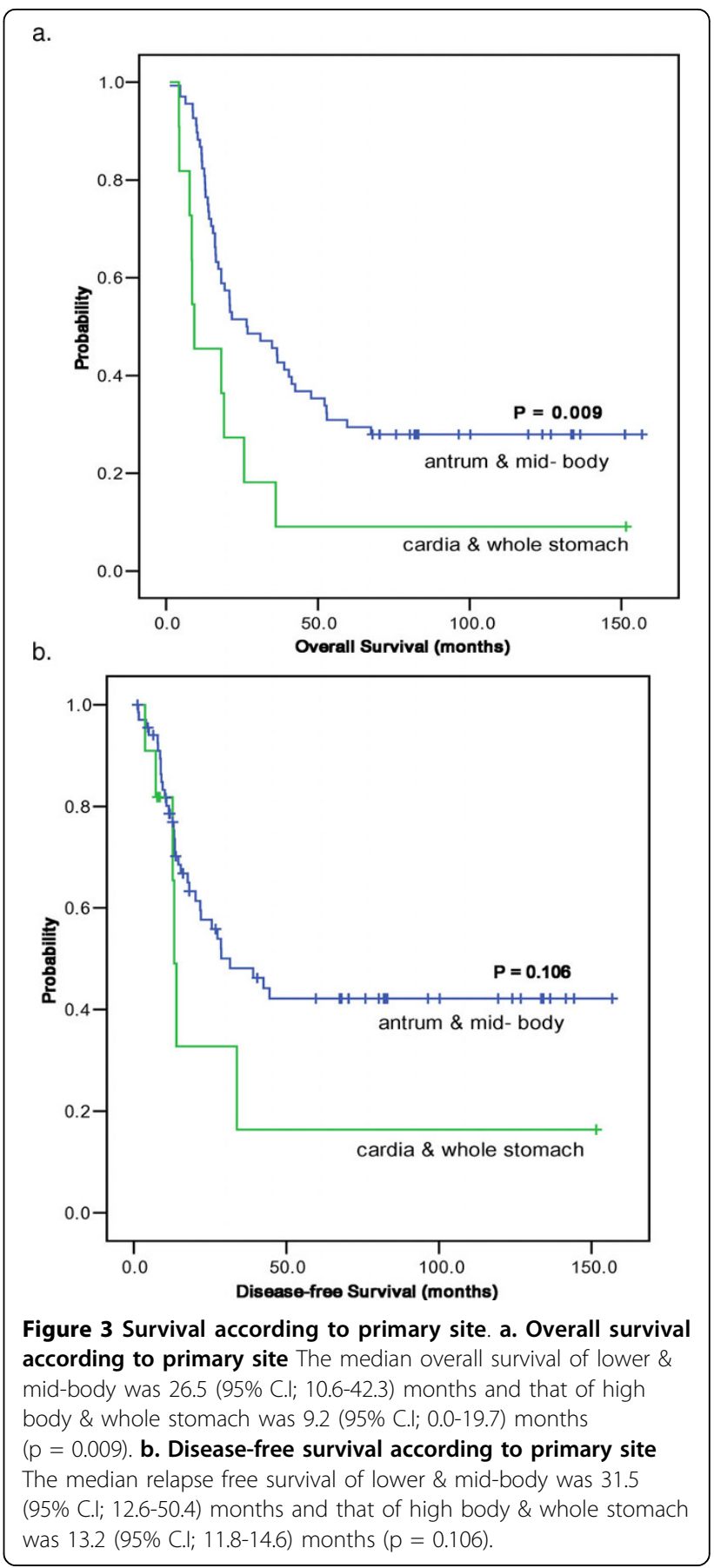

treatment in gastric cancer to find the five-year survival rate was $<15 \%$ in stage IV patients [21].

One of the plausible explanations for significant discrepancy in survival between antral and cardial stomach cancer with hepatoduodenal lymph node and retropancreatic lymph node may owe to different lymphatic drainage system. The antral stomach cancer cells may drain into hepatoduodenal lymph node at earlier stage when compared with those located at cardia for instance. The statistical 
Table 2 Patients' characteristics according to primary sites

\begin{tabular}{|c|c|c|c|}
\hline & Low \& mid-body $(n=68)$ & High body \& whole stomach $(n=11)$ & $P$ value \\
\hline Age (mean) & 56.2 & 57.9 & 0.524 \\
\hline$\overline{\text { Sex }}$ & & & 0.262 \\
\hline Male & $44(35.3 \%)$ & $9(81.8 \%)$ & \\
\hline Female & $24(64.7 \%)$ & $2(18.2 \%)$ & \\
\hline$\overline{\text { ECOG performance status }}$ & & & 0.780 \\
\hline 0 & $8(11.8 \%)$ & $2(18.2 \%)$ & \\
\hline 1 & $59(86.8 \%)$ & $9(81.8 \%)$ & \\
\hline 2 & $1(1.5 \%)$ & 0 & \\
\hline Bormann type & & & 0.033 \\
\hline । & 0 & 0 & \\
\hline$\|$ & $16(23.5 \%)$ & $1(9.1 \%)$ & \\
\hline III & $46(67.6 \%)$ & $6(54.5 \%)$ & \\
\hline IV & $6(8.8 \%)$ & $4(36.4 \%)$ & \\
\hline Lauren classification & & & 0.527 \\
\hline Intestinal & $17(25.0 \%)$ & $3(23.7 \%)$ & \\
\hline Diffuse & $31(45.6 \%)$ & $7(63.6 \%)$ & \\
\hline Mixed & $4(5.9 \%)$ & 0 & \\
\hline Unknown & $16(23.5 \%)$ & $1(9.1 \%)$ & \\
\hline Histological grade & & & 0.390 \\
\hline Well to moderate & $21(30.9 \%)$ & $2(18.2 \%)$ & \\
\hline Poor to undifferentiated & $47(69.1 \%)$ & $9(81.8 \%)$ & \\
\hline Type of gastrectomy & & & $<0.001$ \\
\hline Total gastrectomy & $26(38.2 \%)$ & $11(100 \%)$ & \\
\hline Subtotal gastrectomy & $42(61.8 \%)$ & 0 & \\
\hline Extent of surgery & & & $<0.001$ \\
\hline Resection of spleen & $9(13.2 \%)$ & $6(54.5 \%)$ & \\
\hline Resection of distal pancreas & $2(2.9 \%)$ & $1(9.1 \%)$ & \\
\hline Resection of spleen, pancreas & 0 & $2(18.2 \%)$ & \\
\hline T staging & & & 0.543 \\
\hline $\mathrm{T} 1$ & 0 & 0 & \\
\hline $\mathrm{T} 2$ & 27 (39.7\%) & $3(27.3 \%)$ & \\
\hline T3 & $35(51.5 \%)$ & $6(54.5 \%)$ & \\
\hline T4 & $6(8.8 \%)$ & $2(18.2 \%)$ & \\
\hline $\mathrm{N}$ staging & & & 0.066 \\
\hline $\mathrm{N} 1$ & $14(20.6 \%)$ & 0 & \\
\hline N2 & $23(33.8 \%)$ & $2(18.2 \%)$ & \\
\hline N3 & $31(45.6 \%)$ & $9(81.8 \%)$ & \\
\hline No. of dissected LNs (mean) & 43.3 & 52.8 & 0.157 \\
\hline Metastatic lymph node station & & & 0.701 \\
\hline$\# 12$ & $59(86.8 \%)$ & $10(90.9 \%)$ & \\
\hline$\# 13$ & $9(13.2 \%)$ & $1(9.1 \%)$ & \\
\hline Post-operation treatment & & & 0.553 \\
\hline None & $17(25.0 \%)$ & $4(36.4 \%)$ & \\
\hline Chemotherapy & $41(60.3 \%)$ & $7(63.6 \%)$ & \\
\hline Chemo-radiation & $8(11.8 \%)$ & 0 & \\
\hline Unknown & $2(2.9 \%)$ & 0 & \\
\hline Lymph node dissection & & & 0.007 \\
\hline D2 & 67 (98.5\%) & $9(81.8 \%)$ & \\
\hline D3 & $1(1.5 \%)$ & $2(18.2 \%)$ & \\
\hline
\end{tabular}


Table 3 Univariate analysis of prognostic factors for patients with metastatic lymph node positive gastric cancer

\begin{tabular}{|c|c|c|c|c|c|}
\hline & $1 \mathrm{YSR}$ & 3 YSR & Median OS $\left(95 \%\right.$ C.I $\left.{ }^{\mathrm{a}}\right)$ months & H.R $\left(95 \%\right.$ C.I $\left.{ }^{\mathrm{a}}\right)$ & $\mathrm{P}$ value \\
\hline Age & & & & & 0.461 \\
\hline$<65$ & $82.1 \%$ & $42.9 \%$ & $25.6(11.0-40.2)$ & 1.0 & \\
\hline$>65$ & $65.2 \%$ & $39.1 \%$ & $19.2(11.8-26.6)$ & $1.232(0.707-2.145)$ & \\
\hline Sex & & & & & 0.204 \\
\hline Male & $77.4 \%$ & $47.2 \%$ & $31.0(15.2-46.9)$ & 1.0 & \\
\hline female & $76.9 \%$ & $30.8 \%$ & $16.1(11.9-20.2)$ & $1.416(0.828-2.421)$ & \\
\hline ECOG P.S & & & & & 0.464 \\
\hline 0 & $80.0 \%$ & $40.0 \%$ & $20.9(0.0-49.6)$ & 1.0 & \\
\hline 1 & $76.5 \%$ & $42.7 \%$ & $21.0(12.2-29.8)$ & $0.776(0.381-1.582)$ & \\
\hline 2 & $100 \%$ & $0 \%$ & $13.9(13.9-13.9)$ & $2.304(0.285-18.624)$ & \\
\hline Primary site & & & & & 0.012 \\
\hline Low \& mid-body & $82.4 \%$ & $45.6 \%$ & $26.5(10.6-42.3)$ & 1.0 & \\
\hline High body \& whole stomach & $45.5 \%$ & $18.2 \%$ & $9.2(0.0-19.7)$ & $2.417(1.216-4.806)$ & \\
\hline Bormann type & & & & & 0.031 \\
\hline \multicolumn{6}{|l|}{ । } \\
\hline$\|$ & $82.4 \%$ & $58.8 \%$ & 52.9 & 1.0 & \\
\hline III & $78.9 \%$ & $42.3 \%$ & $21.7(7.8-35.6)$ & $1.845(0.895-3.803)$ & \\
\hline IV & $60.0 \%$ & $10.0 \%$ & $13.0(9.8-16.1)$ & $3.521(1.379-8.991)$ & \\
\hline Lauren classification & & & & & 0.207 \\
\hline Intestinal & $75.0 \%$ & $30.0 \%$ & $16.3(15.7-16.8)$ & 1.0 & \\
\hline Diffuse & $78.9 \%$ & $57.9 \%$ & $38.9(31.0-46.8)$ & $0.659(0.344-1.233)$ & \\
\hline Mixed & $75.0 \%$ & $25.0 \%$ & $14.1(0.0-29.0)$ & $0.920(0.266-3.181)$ & \\
\hline Unknown & $76.5 \%$ & $23.5 \%$ & $15.5(12.3-18.7)$ & $1.274(0.622-2.610)$ & \\
\hline Histological grade & & & & & 0.954 \\
\hline Well to moderate & $86.9 \%$ & $39.1 \%$ & $20.8(16.4-25.2)$ & 1.0 & \\
\hline Poor to undifferentiated & $73.2 \%$ & $42.9 \%$ & $21.7(5.9-37.5)$ & $1.017(0.578-1.787)$ & \\
\hline Type of gastrectomy & & & & & 0.014 \\
\hline Total gastrectomy & $70.3 \%$ & $29.3 \%$ & $17.1(13.2-21.1)$ & $1.913(1.143-3.203)$ & \\
\hline Subtotal gastrectomy & $83.3 \%$ & $52.4 \%$ & $36.6(13.9-59.3)$ & 1.0 & \\
\hline Extent of surgery & & & & & 0.006 \\
\hline None & $81.4 \%$ & $49.2 \%$ & $34.9(16.4-53.4)$ & 1.0 & \\
\hline Resection of spleen & $60.0 \%$ & $20.0 \%$ & $13.0(9.7-16.2)$ & $2.937(1.604-5.337)$ & \\
\hline Resection of distal pancreas & $66.7 \%$ & $33.3 \%$ & $16.1(0.0-34.9)$ & $1.353(0.327-5.606)$ & \\
\hline Resection of spleen, pancreas & $100 \%$ & $0 \%$ & 18.1 & $1.953(0.466-8.195)$ & \\
\hline T staging & & & & & 0.116 \\
\hline \multicolumn{6}{|l|}{$\mathrm{T} 1$} \\
\hline $\mathrm{T} 2$ & $80.0 \%$ & $56.7 \%$ & $38.9(3.9-73.9)$ & 1.0 & \\
\hline T3 & $75.6 \%$ & $31.7 \%$ & $19.1(14.3-23.8)$ & $1.797(1.010-3.198)$ & \\
\hline T4 & $75.0 \%$ & $37.5 \%$ & $16.1(0.0-32.6)$ & $1.861(0.775-4.468)$ & \\
\hline $\mathrm{N}$ staging & & & & & $<0.001$ \\
\hline N1 & $92.9 \%$ & $71.4 \%$ & $59.6(32.9-86.3)$ & 1.0 & \\
\hline N2 & $88.0 \%$ & $60.0 \%$ & $52.2(35.4-69.0)$ & $1.121(0.470-2.674)$ & \\
\hline N3 & $65.0 \%$ & $20.0 \%$ & $14.8(9.7-19.9)$ & $3.870(1.770-8.463)$ & \\
\hline No. of dissected LNs & & & & & 0.810 \\
\hline$<40$ & $75.8 \%$ & $42.4 \%$ & $25.6(4.7-46.6)$ & $1.065(0.637-1.781)$ & \\
\hline$>40$ & $78.3 \%$ & $41.3 \%$ & $20.8(11.1-30.5)$ & 1.0 & \\
\hline Metastatic lymph node station & & & & & 0.230 \\
\hline$\# 12$ & $76.8 \%$ & $39.1 \%$ & $20.8(12.2-29.4)$ & 1.0 & \\
\hline$\# 13$ & $80.0 \%$ & $60.0 \%$ & $47.7(0.4-95.0)$ & $0.596(0.256-1.388)$ & \\
\hline
\end{tabular}


Table 3: Univariate analysis of prognostic factors for patients with metastatic lymph node positive gastric cancer (Continued)

\begin{tabular}{lcccc}
\hline Post-operative treatment & & & \\
\hline None & $57.1 \%$ & $38.1 \%$ & $14.8(5.4-24.1)$ & 1.0 \\
Chemotherapy & $83.3 \%$ & $37.5 \%$ & $21.0(11.6-30.5)$ & $0.869(0.484-1.562)$ \\
Chemo-radiation & $100 \%$ & $75.0 \%$ & 11.6 & $0.266(0.078-0.916)$ \\
Unknown & $50.0 \%$ & $0 \%$ & $1.020(0.234-4.444)$ \\
\hline Lymph node dissection & & & $21.0(8.3-33.8)$ & 1.0 \\
D2 & $76.3 \%$ & $43.4 \%$ & $18.1(15.2-21.0)$ & $1.739(0.536-5.643)$ \\
D3 & $100 \%$ & $0 \%$ & & 0.357 \\
\hline
\end{tabular}

${ }^{a}$ C.l; confidence interval

significance of primary tumor site should be further validated in larger series of patients. Considering a marked survival discrepancy between the two groups, LN\#12 or\#13 metastasis should be further categorized according to primary tumor locations in future staging system.

Because lymph node metastases occur relatively early in gastric cancer, regional lymphadenectomy is the standard surgical procedure in addition to radical gastrectomy [1]. However, the extent of lymphadenectomy to achieve the optimal outcome is still controversial, and there is no worldwide consensus. Controversy exists regarding the extent of lymph node dissection, and whether it should be limited to the perigastric lymph nodes (D1) or include the regional lymph nodes outside the perigastric area (D2) [22]. The appropriate extent of lymph-node dissection for gastric cancer continues to be debated. Radical lymphadenectomy did not increase long-term survival after curative gastrectomy in either the landmark Medical Research Council trial [23] or in the Dutch [24] gastric trial. However, many proponents of radical lymphadenectomy report benefit of radical or extended radical lymphadenectomy. In a randomized trial comparing D1 to D2/D3 lymph node dissection, patients with D3 dissection showed an absolute overall survival benefit of $5.9 \%$ (95\% CI; 7.3-19.1, log-rank p = 0.041) when compared with the control group [25]. Recently, another study demonstrated survival benefit of D2 or greater lymaphadenectomy over D1 surgery and concluded that given the nodal diffusion in their gastric

Table 4 Multivariate analysis of prognostic factors for patients with metastatic lymph node positive gastric cancer

\begin{tabular}{cccc}
\hline Factor & Relative risk & $\mathbf{9 5 \%}$ C.I. & P value \\
\hline Type of gastrectomy & 0.875 & $0.473-1.619$ & 0.570 \\
Extent of surgery & 1.143 & $0.725-1.802$ & 0.565 \\
Bormann type & 1.402 & $0.810-2.425$ & 0.227 \\
T staging & 1.141 & $0.723-1.801$ & 0.570 \\
N staging & 2.033 & $1.305-3.167$ & 0.002 \\
Primary site & 1.063 & $0.386-2.924$ & 0.906 \\
\hline
\end{tabular}

${ }^{a}$ C.l; confidence interval cancer patients, extended lymphadenectomy is still a rationale to obtain radical resection [15].

Given a considerable difference in survival according to lymph node stations and primary tumor sites, extended lymphadenectomies may also be crucial in accurately staging the tumor. The LN\#12 and higher stations are not generally removed in D1 dissection and in such case, there is a chance of misleading migration to a lower stage. Although criticized by postoperative complications in D2 or higher lymphadenectomies $[23,24]$, recent studies showed no difference in the incidence of major complications or mortality between D1 and D2 dissections [26,27]. Notably, there was no significant difference in quality of life (QOL) after gastrectomy with D1 and D2/D3 lymphadenectomies [28]. Therefore, gastrectomy with extended lymphadenectomy may be beneficial not only in terms of survival but also accurate pathologic $\mathrm{N}$ staging.

This study is limited by small number of patients and intrinsic bias from retrospective analysis in nature. Our result should be interpreted with caution because it represents only a small group of patients with gastric cancer and the LN\#12a and other lymph nodes of the hepatoduodenal ligament were not evaluated separately. Prospective evaluation of outcomes in subset of gastric cancer patients with LN\#12 or \#13 metastasis is definitely warranted especially with regards to primary tumor location.

\section{Conclusions}

In this study, we found that curatively resected gastric cancer patients with pathologic involvement of LN \#12 and/or LN \#13 had favorable survival outcome, especially those with primary tumor location of mid-body to antrum.

\footnotetext{
Acknowledgements

We thank Ms Min Ji Kang for editorial assistance. This study was supported in part by a grant of the Korea Health 21 R\&D Project, Ministry of Health \& Welfare, Republic of Korea (0412-CR01-0704-0001).

Author details

'Division of Hematology and Oncology, Department of Medicine, Samsung
} Medical Center, Sungkyunkwan University School of Medicine, Seoul, Korea. 
${ }^{2}$ Division of Hematology and Oncology, Department of Internal Medicine, Hallym University Medical Center, Hallym University College of Medicine, Seoul, Korea. ${ }^{3}$ Department of Surgery, Samsung Medical Center, Sungkyunkwan University School of Medicine, Seoul, Korea. ${ }^{4}$ Department of Pathology, Samsung Medical Center, Sungkyunkwan University School of Medicine, Seoul, South Korea. ${ }^{5}$ Current address: Department of Surgery, Yonsei University College of Medicine, Seoul, Korea.

\section{Authors' contributions}

DHL, SHK and SHP drafted the manuscript. DHL, JL, SHP, SHJ, MJP and SYY collected the data and performed the statistical analysis. YSP, JL, SHP, HYL, JYA, TSS, JHN, JMB, SK and WKK followed the patients. CKP performed pathologic evaluations. YSP and WKK designed the study and helped with the manuscript. All authors read and approved the final manuscript.

\section{Competing interests}

The authors declare that they have no competing interests.

Received: 11 October 2008

Accepted: 29 January 2010 Published: 29 January 2010

\section{References}

1. Shin HR, Jung KW, Won YJ, Kong HJ, Yim SH, Sung J, Seo SW, Kim KY, Lee SY, Kong IS, et al: National cancer incidence for the year 2002 in Korea. Cancer Res Treat 2007, 39(4):139-149.

2. Karpeh MS, Leon L, Klimstra D, Brennan MF: Lymph node staging in gastric cancer: is location more important than Number? An analysis of 1,038 patients. Ann Surg 2000, 232(3):362-371.

3. Siewert JR, Bottcher K, Stein HJ, Roder JD: Relevant prognostic factors in gastric cancer: ten-year results of the German Gastric Cancer Study. Ann Surg 1998, 228(4):449-461.

4. Hermanek P, Sobin LH: UICC TNM Classification of Malignant Tumors. Belin: Springer, 41987.

5. Oliver HB, Donald EH, Robert VP, Hutter BJ, Kennedy : Manual for Staging of Cancer, American Joint Committee on Cancer, 4th ed. Philadelphia: JB Lippincott 1992.

6. Fleming I, Cooper JS, Henson DE, et al: Manual for Staging of Cancer, American Joint Committee on Cancer, 5th ed. Philadelphia: JB Lippincott 1997.

7. Greene F, Page D, Morrow M: AJCC Cancer Staging Manual, 6th ed. New York: Springer 2002.

8. Sobin L, Wittekind C: UICC TNM Classification of Malignant Tumors, 5th ed. New York: Wiley-Liss 1997.

9. Sobin L, Wittekind C: International Union Against Cancer (UICC): TNM Classification of Malignant Tumors, 6th ed. New York: Wiley 2002.

10. Roder JD, Bottcher K, Busch R, Wittekind C, Hermanek P, Siewert JR. Classification of regional lymph node metastasis from gastric carcinoma. German Gastric Cancer Study Group. Cancer 1998, 82(4):621-631.

11. Japanese Gastric Cancer A: Japanese Classification of Gastric Carcinoma 2nd English Edition. Gastric Cancer 1998, 1(1):10-24.

12. HC Chung HY, Lim EK, Kim JH, Roh JK, et al: Should All the N3 Lymph Nodes Group Metastasis Be Regarded as Distant Metastasis (M1) in Curatively Resected Gastric Cancer? Yonsei Medical Journal 1992, 33(2):143-152.

13. Lim S, Muhs BE, Marcus SG, Newman E, Berman RS, Hiotis SP: Results following resection for stage IV gastric cancer; are better outcomes observed in selected patient subgroups? J Surg Oncol 2007, 95(2):118-122.

14. Medina-Franco H, Contreras-Saldivar A, Ramos-De La Medina A, PalaciosSanchez P, Cortes-Gonzalez R, Ugarte JA: Surgery for stage IV gastric cancer. Am J Surg 2004, 187(4):543-546.

15. Di Leo A, Marrelli D, Roviello F, Bernini M, Minicozzi A, Giacopuzzi S, Pedrazzani C, Baiocchi LG, de Manzoni G: Lymph node involvement in gastric cancer for different tumor sites and T stage: Italian Research Group for Gastric Cancer (IRGGC) experience. I Gastrointest Surg 2007, 11(9):1146-1153.

16. Hagiwara A, Takahashi T, Sawai K, Iwamoto A, Shimotsuma M, Yoneyama C, Seiki K, Itoh M, Sasabe T, Lee M: Lymph nodal vital staining with newer carbon particle suspensions compared with India ink: experimental and clinical observations. Lymphology 1992, 25(2):84-89.

17. Takahashi T, Sawai K, Hagiwara A, Takahashi S, Seiki K, Tokuda H: Typeoriented therapy for gastric cancer effective for lymph node metastasis: management of lymph node metastasis using activated carbon particles adsorbing an anticancer agent. Semin Surg Oncol 1991, 7(6):378-383.

18. Park JM, Park SS, Mok YJ, Kim CS: pN3MO gastric cancer: the category that allows the sub-classification of stage-IV gastric cancer (IVa and IVb). Ann Surg Oncol 2007, 14(9):2535-2542.

19. Kim J, Cheong JH, Hyung WJ, Shen J, Choi SH, Noh SH: Predictors of longterm survival in pN3 gastric cancer patients. J Surg Oncol 2004, 88(1):9-13.

20. Kattan MW, Karpeh MS, Mazumdar M, Brennan MF: Postoperative nomogram for disease-specific survival after an Ro resection for gastric carcinoma. J Clin Oncol 2003, 21(19):3647-3650.

21. Kim S, Lim do H, Lee J, Kang WK, Macdonald JS, Park CH, Park SH, Lee SH, Kim K, Park JO, et al: An observational study suggesting clinical benefit for adjuvant postoperative chemoradiation in a population of over 500 cases after gastric resection with D2 nodal dissection for adenocarcinoma of the stomach. Int I Radiat Oncol Biol Phys 2005, 63(5):1279-1285

22. Velde van de CJ: Resection for gastric cancer in the community. Semin Oncol 2005, 32(6 Suppl 9):S90-93.

23. Cuschieri A, Weeden S, Fielding J, Bancewicz J, Craven J, Joypaul V, Sydes $M$, Fayers $P$ : Patient survival after $D 1$ and $D 2$ resections for gastric cancer: long-term results of the MRC randomized surgical trial. Surgical Co-operative Group. Br J Cancer 1999, 79(9-10):1522-1530.

24. Hartgrink $\mathrm{HH}$, Velde van de CJ, Putter $\mathrm{H}$, Bonenkamp JJ, Klein Kranenbarg $\mathrm{E}_{\text {, }}$ Songun I, Welvaart K, van Krieken JH, Meijer S, Plukker JT, et al: Extended lymph node dissection for gastric cancer: who may benefit? Final results of the randomized Dutch gastric cancer group trial. J Clin Oncol 2004, 22(11):2069-2077.

25. Wu CW, Hsiung CA, Lo SS, Hsieh MC, Chen JH, Li AF, Lui WY, WhangPeng J: Nodal dissection for patients with gastric cancer: a randomised controlled trial. Lancet Oncol 2006, 7(4):309-315.

26. Sano T, Sasako M, Yamamoto S, Nashimoto A, Kurita A, Hiratsuka M, Tsujinaka T, Kinoshita T, Arai K, Yamamura Y, et al: Gastric cancer surgery: morbidity and mortality results from a prospective randomized controlled trial comparing D2 and extended para-aortic lymphadenectomy-Japan Clinical Oncology Group study 9501. J Clin Oncol 2004, 22(14):2767-2773.

27. Wu CW, Chang IS, Lo SS, Hsieh MC, Chen JH, Lui WY, Whang-Peng J: Complications following D3 gastrectomy: post hoc analysis of a randomized trial. World J Surg 2006, 30(1):12-16.

28. Wu CW, Chiou JM, Ko FS, Lo SS, Chen JH, Lui WY, Whang-Peng J: Quality of life after curative gastrectomy for gastric cancer in a randomised controlled trial. Br J Cancer 2008, 98(1):54-59.

\section{Pre-publication history}

The pre-publication history for this paper can be accessed here: http://www. biomedcentral.com/1471-2407/10/25/prepub

doi:10.1186/1471-2407-10-25

Cite this article as: Lim et al:: Metastatic lymph node in gastric cancer; Is it a real distant metastasis? BMC Cancer 2010 10:25.

\section{Submit your next manuscript to BioMed Central and take full advantage of:}

- Convenient online submission

- Thorough peer review

- No space constraints or color figure charges

- Immediate publication on acceptance

- Inclusion in PubMed, CAS, Scopus and Google Scholar

- Research which is freely available for redistribution 